1 Instituto Sul-Americano de Governo em Saúde/ União de Nações SulAmericanas (Isags/

Unasul) - Rio de Janeiro (RJ), Brasil.

marianafaria@isagsunasur.org

2 Fundacão Oswaldo Cruz (Fiocruz), Escola Nacional de Saúde Pública Sergio Arouca (Ensp) - Rio de Janeiro (RJ), Brasil. giovanel@ensp.fiocruz.br

3 Instituto Sul-Americano de Governo em Saúde/ União de Nações Sul-

Americanas (Isags/

Unasul) - Rio de Janeiro

(RJ), Brasil.

luanabermudez@isags-

unasur.org

\section{A Unasul na Assembleia Mundial da Saúde: posicionamentos comuns do Conselho de Saúde Sul-Americano}

\author{
Unasur in the World Health Assembly: common positions of the \\ South American Health Council
}

Mariana Faria', Ligia Giovanella², Luana Bermudez $\mathbf{3}$

\begin{abstract}
RESUMO A União de Nações Sul-Americanas (Unasul), criada em 2008, pretende fortalecer a identidade sul-americana e reduzir inequidades regionais. Com a criação de conselho específico, a saúde ganha destaque como área estratégica. O artigo discute a atuação do Conselho de Saúde da Unasul na Assembleia Mundial da Saúde (AMS), a partir da análise dos posicionamentos comuns do bloco de 2010 a 2014 . No período analisado, a Unasul apresentou posições comuns referentes a 26 Resoluções. A atuação da Unasul na AMS ao longo dos últimos cinco anos dá visibilidade ao processo de integração regional na América do Sul e fortalece a própria Unasul como um player na agenda global da saúde.
\end{abstract}

PALAVRAS-CHAVE Cooperação internacional; Saúde global; Organização Mundial da Saúde; Diplomacia em saúde; Cooperação Sul-Sul.

ABSTRACT The Union of the South American Nations (Unasur), created in 2008, aims to strengthen the South American identity and reduce regional inequities. With the creation of specific council, health is highlighted as strategic area. The article discusses the performance of the Unasur Health Council in the World Health Assembly (WHA), from the analysis of the common positions of the bloc from 2010 to 2014. In the analyzed period, Unasur has presented common positions regarding to 26 Resolutions. Unasur actuation in the WHA over the last five years brings visibility to the regional integration process in South America and strengthens Unasur as a player in the global health agenda.

KEYWORDS International cooperation; Global health; World Health Organization; Health diplomacy; South-South cooperation. 


\section{Introdução}

As tentativas em torno da obtenção de consensos na definição de políticas, na promoção de assessorias e assistência técnica, bem como no estabelecimento de redes de colaboração em áreas específicas do campo da saúde têm sido cada vez mais frequentes entre países da América do Sul. Esses consensos e processos de cooperação e colaboração na área da saúde têm gerado acordos mais amplos, que por vezes evoluem para a "formação de comunidades ou blocos regionais" (SANTANA, 2011, P. 2996). Exemplos dessas conformações são o Organismo Andino de SaúdeConvênio Hipólito Unanue (Oras-Conhu), da Comunidade Andina (CAN); o Subgrupo de Trabalho 11 Saúde (SGT 11), do Mercado Comum do Sul (Mercosul); e o Conselho de Saúde Sul-Americano (CSS), da União de Nações Sul-Americanas (Unasul). O CSS é um arranjo intergovernamental no campo da 'cooperação Sul-Sul' e da 'diplomacia da saúde', que traz novas perspectivas em saúde para países em desenvolvimento (BUSS; FERREIRA, 2011).

A Unasul foi criada como resposta contra-hegemônica à proposta de constituição da Aliança de Livre Comércio das Américas (Alca). Em 2005, durante o IV Encontro das Américas, em Mar del Plata, Buenos Aires, Chefes de Estado de tendência progressista e movimentos antiglobalização expressaram sua rejeição à criação da Alca e iniciaram um novo projeto com vistas a alcançar modalidades alternativas de governança regional, que resultou no nascimento da União de Nações Sul-Americanas. A Unasul firmou-se como um projeto de integração alternativo com compromissos renovados sobre os princípios da democracia, da inclusão social e dos direitos humanos.

A saúde, nesse contexto, tornou-se uma importante arena de integração e de promoção do direito à saúde baseado na universalidade, equidade e integralidade. A partir da criação do CSS, com seus grupos técnicos e suas redes estruturantes, a Unasul parte para implementar projetos de saúde, criando espaços habilitados para a troca de conhecimentos, e gerando estratégias regionais que têm apoiado a coordenação de posições comuns dos países em fóruns multilaterais, fortalecendo a atuação do bloco como um player global em saúde.

O objetivo desta reflexão é identificar de que modo a atuação da Unasul, por meio de posicionamentos comuns na Assembleia Mundial da Saúde (AMS), contribui para o fortalecimento do processo de integração regional na América do Sul, para a construção de uma agenda regional em saúde e para a consolidação da própria Unasul como um player global na definição de pautas, na agenda mundial da saúde, que possam contribuir para a redução de inequidades em saúde.

\section{Método}

Para a análise da atuação da Unasul na Assembleia Mundial da Saúde, foram identificadas as Resoluções da AMS sobre as quais a Unasul apresentou posicionamentos comuns no período compreendido entre 2010 e 2014. As fontes de informação foram: (i) informes de atividades das Presidências Pro-Tempore (PPTs), do CSS, dos anos de 2010 e 2011; (ii) acervo de documentos do Instituto SulAmericano de Governo em Saúde (Isags), sobre a participação dos Estados-membros da Unasul na AMS, de 2012 a 2014.

A partir da análise desses documentos, foram identificados os posicionamentos comuns na AMS apresentados pelo CSS.

Os informes das PPTs, em 2010 e 2011, permitiram identificar os posicionamentos comuns da Unasul na $63^{\mathrm{a}}$ e na $64^{\mathrm{a}}$ AMS. Foram elaborados pelo Ministério da Saúde do Equador, período de 2009-2010, e pelo Ministério da Saúde do Uruguai, período de 2010-2011, possuindo, assim, distintos níveis de informações e detalhamentos sobre os posicionamentos comuns da Unasul na AMS. $\mathrm{O}$ informe do Equador detalha a atuação do 
CSS na $63^{\mathrm{a}}$ AMS, informando desde o processo de construção de consenso e dos atores protagonistas até o conteúdo dos posicionamentos comuns apresentados. O informe do Uruguai apresenta menor detalhamento, menciona a atuação conjunta do bloco na 64 ${ }^{\text {a }}$ AMS e identifica os temas abordados pelos posicionamentos comuns, porém, sem citar a numeração ou o título das Resoluções da AMS, tampouco o conteúdo dos posicionamentos comuns apresentados.

O Isags foi inaugurado em julho de 2011 e seu acompanhamento da participação da Unasul na AMS iniciou-se em 2012, a partir da $65^{\mathrm{a}}$ AMS. Desde então, o instituto produz relatórios internos da Direção Executiva sobre o tema e os divulga parcialmente em seu informe de atividades anual, no informe de maio e em seu site (www.isags-unasul.org). Os informes do Isags permitiram conhecer os posicionamentos comuns das AMS 65a $66^{\mathrm{a}}$ e $67^{\mathrm{a}}$.

As decisões da AMS tomam a forma de Resoluções, que não são vinculantes e visam gerar recomendações globais. As Resoluções da Organização Mundial de Saúde (OMS), uma vez aprovadas, produzem diretrizes em políticas de saúde, em nível global, que devem ser implementadas nos países (PERMANENT MISSION OF SWITZERLAND TO THE UNITED NATIONS, 2011). Para ter acesso aos textos finais das Resoluções da AMS no período estudado, realizou-se pesquisa no site da OMS (http://www.who.int/ mediacentre/events/governance/wha/en/).

Dentre o conjunto das Resoluções das cinco AMS estudadas, foram selecionadas aquelas relativas aos posicionamentos comuns da Unasul identificados.

As Resoluções selecionadas com posicionamentos comuns foram agrupadas conforme as cinco linhas prioritárias definidas no Plano Quinquenal 2010-2015, do CSS, e foi realizada uma análise temática de seus conteúdos. Para contextualizar a analise da atuação do CSS, com foco específico em seu papel de formulador e negociador de políticas em fóruns globais, em especial na AMS, descrevem-se inicialmente a conformação, a estrutura e os objetivos da Unasul e de seu Conselho de Saúde. Em seguida, apresentam-se a estrutura e o funcionamento da AMS. Além disto, são mencionadas participações de outros blocos regionais na AMS, como a União Africana, a Comunidade do Caribe, com especial atenção para o caso da União Europeia, por suas singularidades de representação unificada perante as Nações Unidas, traçando paralelos com a experiência da Unasul. Passa-se, então, a analisar as Resoluções selecionadas.

\section{A Unasul e o Conselho de Saúde Sul-Americano}

A Unasul é composta dos 12 países independentes, da América do Sul, com o objetivo de construir uma identidade e uma cidadania sul-americana, e desenvolver um espaço de integração e união nos âmbitos cultural, social, econômico, político, ambiental, energético e de infraestrutura (UNASUR, 2008A). Sua estrutura é dividida entre vertical e horizontal. A estrutura vertical é composta pelo Conselho de Chefes de Estado e de Governo, Conselho de Ministros, Conselho de Delegados, além de uma Secretaria Geral, com sede na cidade de Quito, Equador. A estrutura horizontal conta com 12 Conselhos Setoriais ministeriais, que tratam de temas específicos, como infraestrutura, educação, defesa e saúde, entre outros. Esta estrutura conta ainda com dois centros de pensamento estratégico: um atrelado ao Conselho de Defesa e outro, ao Conselho de Saúde Sul-Americano. A Presidência Pro Tempore (PPT) da Unasul é anual e rotativa, ocupada em ordem alfabética pelos países do bloco.

O CSS foi criado na primeira Reunião do Conselho de Chefas e Chefes de Estado e de Governo do bloco, em 2008, com o objetivo de consolidar a América do Sul como um espaço de integração em saúde que contribua para a saúde de todos e para o desenvolvimento, incorporando e integrando os esforços e avanços sub-regionais. Foi instituído 
a partir do consenso de que a saúde é um direito fundamental do ser humano e da sociedade, além de ser um componente vital para o desenvolvimento humano e para a integração regional (UNASUR, 2008A).

É composto pelos ministros da saúde dos doze Estados-membros da Unasul e sua estrutura inclui um comitê coordenador, formado por representantes dos ministérios de cada Estado-membro, cinco Grupos Técnicos (GTs) e seis Redes Estruturantes. Os ministros da saúde da Unasul estabeleceram, em 2010, uma Agenda Sul-Americana de Saúde, que foi posteriormente consolidada pelos GTs em um Plano de Trabalho Quinquenal 2010-2015, com cinco eixos prioritários do CSS (UNASUR, 2010; BUSS, 2011): Vigilância e resposta em saúde; Desenvolvimento de sistemas de saúde universais; Acesso universal a medicamentos; Promoção à saúde e ação sobre seus determinantes sociais; e Desenvolvimento e gestão de recursos humanos em saúde.

Em julho de 2011, o CSS inaugurou, na cidade do Rio de Janeiro (RJ), o Isags, centro de pensamento estratégico que tem como objetivo colocar à disposição dos Ministérios da Saúde dos Estados-membros da Unasul as melhores práticas e evidências para a gestão em saúde, por meio da promoção de intercâmbio, reflexão crítica, gestão do conhecimento e geração de inovações no campo da política e governança em saúde.

\section{Atuação do Conselho de Saúde Sul-Americano}

O CSS, ao apresentar uma proposta de integração regional baseada na definição da saúde como direito social vinculado à inclusão e a cidadania, marca uma diferença normativa em relação às experiências do Mercosul e da CAN. No Mercosul, os objetivos centrais da Reunião de Ministros da Saúde (RMS) e do SGT 11 são harmonizar legislações e regulamentações, e eliminar obstáculos e barreiras não alfandegárias ao comércio regional de produtos de saúde, enquanto na CAN a saúde foi encarada como uma questão basicamente epidemiológica, focada em problemas entre fronteiras (RIGGIROZZI, 2012; QUEIROZ; GIOVANELLA, 2011).

Desde sua criação, em 2008 até julho de 2015, o CSS realizou oito reuniões ordinárias, nas quais os ministros da saúde da América do Sul debateram e decidiram sobre temas como a epidemia de H1N1, a eleição da direção da Organização Pan-Americana da Saúde (Opas) e a criação de um banco regional de preços de medicamentos.

Além de ser regional, a ação do CSS avança na formulação e na negociação política em fóruns multilaterais. O CSS teria a capacidade de projetar os objetivos regionais no âmbito da diplomacia regional em saúde e defender a região como um espaço geoestratégico na formulação de política internacional, segundo Riggirozzi (2012).

Além da AMS, o CSS tem atuado na formulação e na negociação política em diversos fóruns globais, como o Conselho Diretivo da Opas e as conferências globais realizadas por agências especializadas, como a VI Conferência Internacional das Autoridades Reguladoras de Medicamentos (ICDRA), 2014; o III Fórum Global sobre Recursos Humanos em Saúde, 2013; a VIII Conferência Global em Promoção da Saúde: Saúde em Todas as Políticas, 2013; e a Conferência Mundial sobre Determinantes Sociais da Saúde, 2011. Contudo, sem dúvida, a atuação do CSS na AMS, iniciada em 2010, estabelece um marco histórico para a representação da América do Sul no cenário da diplomacia da saúde global.

\section{Assembleia Mundial da Saúde: estrutura e funcionamento}

A OMS se estrutura em: um órgão plenário, a Assembleia Mundial da Saúde; um órgão executivo, o Conselho Executivo; e seu corpo de funcionários permanente, o secretariado. 
O trabalho do Conselho Executivo e da AMS

é integrado (MINELLI, 2006).

O Conselho Executivo é composto por 34 membros, designado pelos Estadosmembros eleitos pela AMS. O mandato é de três anos e os membros são eleitos em mandatos alternados e por representatividade das regiões (quadro 1). As funções principais do Conselho Executivo são preparatórias e executivas em relação à AMS. A primeira refere-se à definição da agenda da próxima AMS, mas ele também age como o órgão executivo, dando efeito às decisões e políticas aprovadas pela AMS (OMS, 2014A).

O Conselho Executivo se reúne pelo menos duas vezes ao ano: a reunião mais importante ocorre em janeiro e uma segunda reunião ocorre em maio, imediatamente após a AMS. A reunião de janeiro aprova a agenda da AMS que ocorrerá em maio, definida a partir de informes dos comitês regionais, que se reúnem ao longo do segundo semestre do ano anterior (OMS, 2014A).

As duas estruturas deliberativas da OMS possuem processo de deliberação por voto e aprovação por maioria, sendo que cada membro representa um voto. $\mathrm{O}$ quórum mínimo é de $2 / 3$ dos representantes, ou seja, no caso do Conselho Executivo, $2 / 3$ de 34 membros indicados, e no caso da AMS, dos 194 Estados-membros (MINELLI, 2006).

A AMS ocorre anualmente em maio, com a participação das delegações de todos os Estados-membros da OMS, bem como dos organismos intergovernamentais e das organizações não governamentais convidadas (OMS, 2014B). As principais funções da AMS são decidir sobre as políticas da OMS, eleger o Diretor-Geral, supervisionar a execução orçamentária e a administração, e aprovar o programa orçamentário apresentado pelo secretariado.

A AMS se organiza em Plenária, Comitê A e Comitê B. A Plenária reúne todos os participantes da AMS, o Comitê A trata de assuntos técnicos relacionados à saúde e o Comitê $\mathrm{B}$, dos temas financeiros e administrativos da OMS. Nos Comitês se aprovam os textos das Resoluções, que, posteriormente, serão submetidas à plenária.

\begin{tabular}{|c|c|c|c|c|c|}
\hline \multicolumn{6}{|c|}{ Assembleia Mundial da Saúde } \\
\hline Plenária & & & \multicolumn{3}{|c|}{$\begin{array}{l}194 \text { Estados-membros } \\
\text { Organismos intergovernamentais } \\
\text { Organizações não governamentais }\end{array}$} \\
\hline \multicolumn{3}{|l|}{ Comitê A } & \multicolumn{3}{|l|}{ Comitê B } \\
\hline \multicolumn{3}{|c|}{ Assuntos técnicos relacionados à saúde } & \multicolumn{3}{|c|}{ Temas financeiros e administrativos } \\
\hline \multicolumn{6}{|c|}{ Conselho Executivo } \\
\hline África - 7 & Américas - 6 & Europa - 8 & Leste Mediterrâneo - 5 & $\begin{array}{c}\text { Oeste } \\
\text { Pacífico-5 }\end{array}$ & Sudeste Asiático - 3 \\
\hline $\begin{array}{l}\text { África do } \\
\text { Sul } \\
\text { Chade } \\
\text { Congo } \\
\text { Eritreia } \\
\text { Gambia } \\
\text { Libéria } \\
\text { Namíbia }\end{array}$ & $\begin{array}{l}\text { Argentina } \\
\text { Brasil } \\
\text { Cuba } \\
\text { EUA } \\
\text { Panamá } \\
\text { Suriname }\end{array}$ & $\begin{array}{l}\text { Albânia } \\
\text { Andorra } \\
\text { Azerbaijão } \\
\text { Bélgica } \\
\text { Croácia } \\
\text { Lituânia } \\
\text { Reino Unido } \\
\text { Rússia }\end{array}$ & $\begin{array}{l}\text { Arábia Saudita } \\
\text { Egito } \\
\text { Iran } \\
\text { Kuait } \\
\text { Líbano }\end{array}$ & $\begin{array}{l}\text { Austrália } \\
\text { China } \\
\text { Coreia } \\
\text { Japão } \\
\text { Malásia }\end{array}$ & $\begin{array}{l}\text { Coreia } \\
\text { Maldívias } \\
\text { Nepal }\end{array}$ \\
\hline
\end{tabular}

Fonte: Elaboração própria. 
Além dessas três estruturas fixas, podem ser organizadas pelos participantes, durante a AMS, sessões de informação técnica sobre temas específicos (side events), cujo objetivo é apresentar os últimos avanços em distintas áreas, servir de espaço para o debate e facilitar o intercâmbio de informações. A entrada nos Comitês e side events, diferentemente de na Plenária, é restrita a alguns grupos de participantes, não incluindo as organizações não governamentais, nem os representantes do setor privado.

O CSS vem ocupando todos os espaços da OMS a partir de distintas estratégias de atuação. Além da apresentação de posicionamentos comuns na AMS, em ambos os comitês, a Unasul reforçou sua representatividade no Conselho Executivo. Das seis vagas destinadas à região das Américas, Estados-membros da Unasul atualmente ocupam metade. Fortalecer a presença do bloco no Conselho Executivo foi estratégico para garantir que os temas definidos como prioridade pelos países da América do Sul pudessem entrar na agenda da AMS seguinte. A Unasul ainda não organizou nenhum side event como bloco, mas vários dos temas que foram alvos de posicionamentos comuns tiveram side events organizados por um ou mais Estado-membro.

\section{A atuação de blocos regionais na AMS}

Quatro blocos regionais - a União Africana (UA), a Comunidade do Caribe (Caricom), o Sistema de Integração da América Central (Sica) e, especialmente, a União Europeia (UE) - já se utilizavam dos posicionamentos comuns entre os países do bloco para apresentar temas de interesse regional na AMS. A Unasul, diferentemente desses quatro blocos regionais que possuem posições de observadores permanentes, em organismos intergovernamentais como a OMS, não é ainda reconhecida como um bloco de países e, portanto, não possui representação oficial na AMS.

Isso significa que não há um assento na AMS destinado à Unasul e que nenhum representante do bloco pode credenciar-se ou falar na AMS como representante da Unasul. Assim, ainda que os 12 Estadosmembros do bloco entrem em consenso e preparem uma proposta de Resolução a partir de um posicionamento comum, e que esta seja apresentada nos Comitês pela PPT e em nome da Unasul, apenas o país ao qual pertence o representante que apresente a proposta de Resolução será considerado como autor da mesma. Os outros 11 países precisam manifestar posteriormente sua concordância em relação ao posicionamento apresentado, individualmente.

A representação da UE na AMS evoluiu no decorrer dos anos e alcançou status diferenciado a partir de 2011. A UE é membro observador das Nações Unidas desde 1974, e manteve os mesmos direitos que os demais observadores permanentes até 2011, quando a Assembleia Geral da Organização das Nações Unidas (ONU) garantiu à UE amplos direitos, como o de participar dos debates, de se pronunciar juntamente com os Estadosmembros, de submeter propostas e emendas, de réplica e de circulação de documentos (A/65/L.64/Rev.1). Quando os países da UE definem uma posição comum, o representante desta entidade está autorizado a apresentar a proposta do bloco, representando seus 28 membros. Desde 2010, a UE possui uma delegação formal frente à OMS, o que facilita a elaboração e a apresentação de posições comuns na AMS (VAN DE PAS; VAN SCHAIK, 2014).

Assim como a representação da UE, a Unasul também avançou em relação aos outros blocos da região. CAN, Mercosul e OTCA, mais antigos do que a Unasul, não se organizaram para uma atuação conjunta na AMS, o que resultou no não reconhecimento da região sul-americana como um ator importante nessa arena. Contudo, a partir de 2010, com a atuação constante e crescente 
da Unasul na AMS, esse cenário começa a ser alterado (RIGGIROZZI, 2012).

\section{Posicionamentos comuns da Unasul na AMS: análise e resultados}

Nos últimos anos, a OMS e seus órgãos têm buscado tornar-se mais transparentes e acessíveis para seus Estados-membros. Como consequência, a OMS e o tema da saúde global vêm ganhando força na agenda de política internacional dos países e mobilizando atores, com o objetivo de preparar melhor as posições que serão levadas à AMS. Esse exercício incentiva a cooperação entre os países, a fim de apresentar posicionamentos comuns nesse fórum multilateral (VAN DE PAS; VAN SCHAIK, 2014).

Chegar ao consenso em relação a um tema demanda trabalho prévio, e a elaboração dos posicionamentos comuns ocorre tanto em reuniões presenciais como em reuniões virtuais. Os encontros presenciais ocorrem nas reuniões ordinárias e extraordinárias do CSS e do comitê coordenador, em especial, nas reuniões ordinárias realizadas no primeiro semestre de cada ano, que, em geral, ocorrem em março ou abril e antecedem a AMS, e nas extraordinárias realizadas em Genebra, Suíça, durante a própria AMS. Além das reuniões do CSS, reuniões dos GTs, oficinas do Isags e outros fóruns multilaterais também são utilizados pela Unasul para reunir-se e discutir sobre temas que serão futuramente apresentados na AMS como posicionamento comum do bloco. Outro espaço privilegiado para a atuação conjunta do CSS é o Conselho Executivo da OMS. Desde 2013, dos seis representantes das Américas no Conselho Executivo (quadro 1), três são Estadosmembros da Unasul: Argentina, Brasil e Suriname. Além dos espaços presenciais, o comitê coordenador e os GTs realizam várias reuniões virtuais nos meses que antecedem a AMS, a fim de discutir, em detalhes, os textos das Resoluções propostas e de suas intervenções comuns (VENTURA, 2013).

Os temas que entram para o debate e posterior consenso do bloco possuem duas portas de entrada: podem partir de uma das estruturas do CSS, como do GT Acesso universal a medicamentos, ou são apresentados por um país, que tem determinado tema como prioridade nacional e busca, em seus companheiros de bloco, o apoio necessário para avançar com o tema no cenário global. Observa-se que o primeiro movimento é o que inicia o processo de consenso para a AMS, mas, nas Assembleias seguintes, os países vão se apropriando desse espaço favorável de negociação, que é o processo de integração. A construção de uma agenda regional em saúde pode acontecer por ambos os mecanismos, pois, uma vez que os países concordam em abraçar o tema de um dos membros do bloco como uma prioridade regional, todos os 12 países se tornam igualmente responsáveis por ele.

A Unasul defendeu seu primeiro posicionamento comum como bloco em um fórum multilateral de saúde em 2010, na $63^{\mathrm{a}}$ AMS, ano no qual o CSS fortaleceu sua institucionalização com a aprovação de seu primeiro Plano Quinquenal e com a criação dos GTs (UNASUR, 2010). O primeiro posicionamento comum defendido pela Unasul na OMS foi sobre o impacto dos direitos de propriedade intelectual sobre o acesso a medicamentos e o poder de monopólio das empresas farmacêuticas na fixação de preços e decisões sobre genéricos. O posicionamento comum do bloco foi liderado pelo Equador e pela Argentina, que representavam, respectivamente, a PPT e a Coordenação do recém-criado GT Acesso universal a medicamentos.

No período de 2010 a 2014, foram realizadas cinco AMS, tendo sido apresentados posicionamentos comuns da Unasul relativos a 25 Resoluções da Assembleia. O número de Resoluções nas quais a Unasul apresentou posicionamentos comuns aumentou ano a ano, com exceção do ano de 2012 (quadro 
2), quando foi realizada a eleição do novo diretor para a Opas.

Esse debate mobilizou esforços regionais na busca de um nome comum. Uma reunião extraordinária do CSS foi convocada previamente à $65^{\mathrm{a}}$ AMS com o objetivo de ouvir os pretendentes indicados por distintos países da região e tentar alcançar o consenso em torno de um candidato único, que pudesse representar a Unasul. Finalmente, não houve consenso da Unasul em torno de um candidato único e os países da região apoiaram distintos concorrentes. Esse movimento em torno de um candidato único, que pudesse representar o bloco, pode ter influenciado na articulação dos países em torno de outros temas da AMS daquele ano, justificando uma queda, em relação ao ano anterior, no número de Resoluções sobre as quais a Unasul apresentou posicionamento comum na AMS.

Ao longo dos anos, além do aumento no número de Resoluções, ocorreu diversificação nos temas das resoluções que foram objeto de posicionamento comum da Unasul (quadro 2). Em 2010, as duas Resoluções objetos de posicionamento comum do CSS estavam relacionadas com a produção de medicamentos. Nos anos seguintes, esse tema se manteve no foco dos posicionamentos comuns do bloco, mas passou a ser acompanhado por diversos outros, como o Regulamento Sanitário Internacional, em 2011 e 2014; a Reforma da OMS, em 2012 e 2013; e os Objetivos de Desenvolvimento do Milênio (ODM), em 2013 e 2014, entre outros.

Quadro 2. Resoluções da AMS sobre as quais a Unasul apresentou posicionamento comum, 2010-2014

\begin{tabular}{|c|c|c|}
\hline Ano e № AMS & $\begin{array}{c}\text { № de } \\
\text { Resoluções }\end{array}$ & Resolução \\
\hline $\begin{array}{l}2010 \\
63 \text { a AMS }\end{array}$ & 2 & $\begin{array}{l}\text { A63/6 - Saúde pública, inovação e propriedade intelectual: estratégia mundial e } \\
\text { plano de ação } \\
\text { A63/23 - Falsificação de produtos médicos }\end{array}$ \\
\hline & & $\begin{array}{l}\text { A64/4 - Financiamento da OMS no futuro } \\
\text { A64/9 - Implementação do Reglamento Sanitario Internacional (RSI) (2005) }\end{array}$ \\
\hline $\begin{array}{l}2011 \\
64^{a} \text { AMS }\end{array}$ & 5 & $\begin{array}{l}\text { A64/13 - Trabalho para reduzir a mortalidade perinatal e neonatal } \\
\text { A64/16 - Produtos médicos de baixa qualidade, espúrios, com etiquetas } \\
\text { enganosas, falsificados ou de imitação } \\
\text { A64/21 - Prevenção e controle de doenças não transmissíveis }\end{array}$ \\
\hline $\begin{array}{l}2012 \\
65 \text { a AMS }\end{array}$ & 2 & $\begin{array}{l}\text { A65/5 - Reforma da OMS: Informe consolidado da Diretora-Geral } \\
\text { A65/24 - Grupo Consultivo de Especialistas para Pesquisa e Desenvolvimento: } \\
\text { Financiamento e Coordenação (CEWG) }\end{array}$ \\
\hline
\end{tabular}




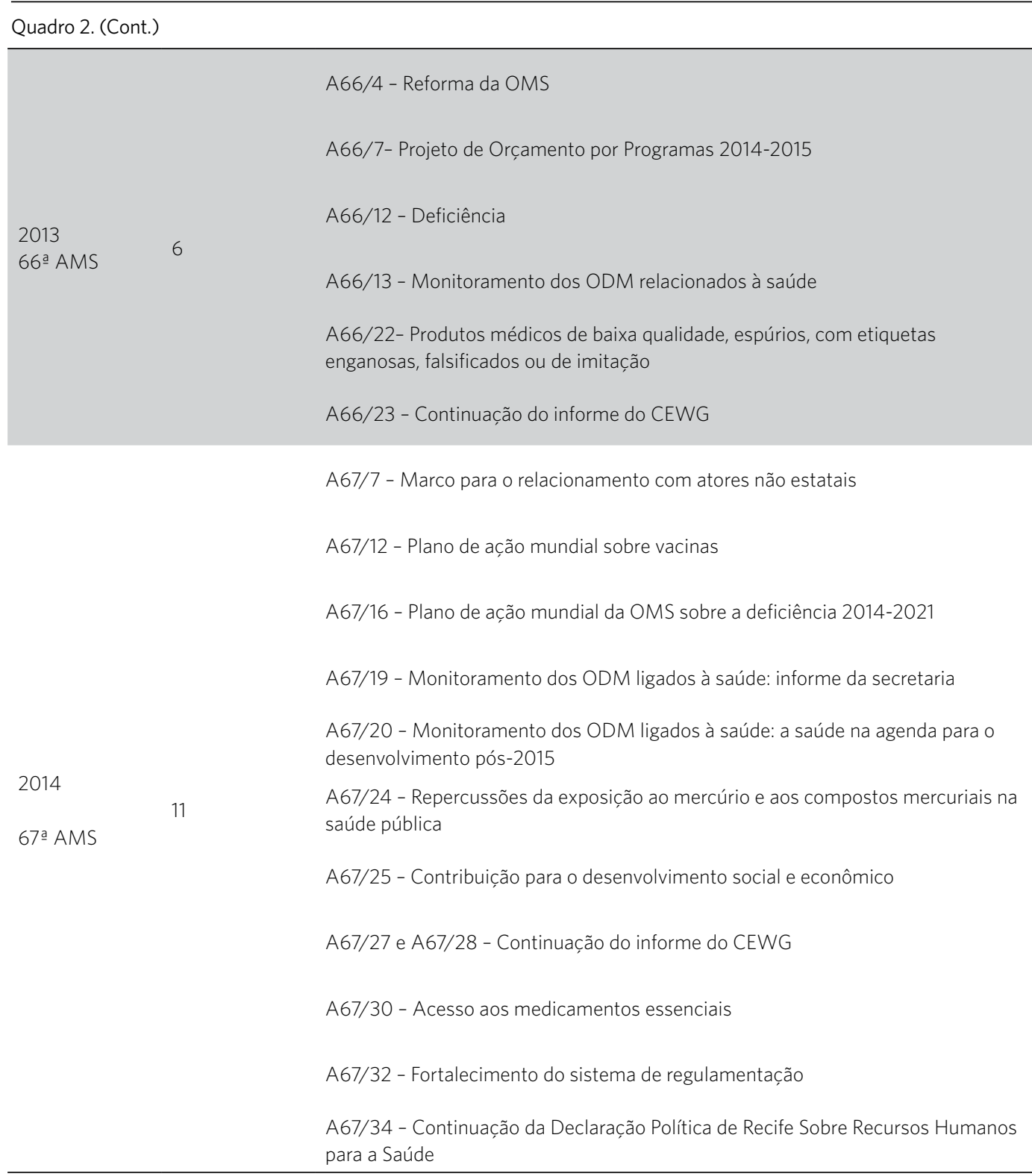

Fonte: Elaboracão própria.

No período analisado, os temas financeiros e administrativos, tratados no Comitê $\mathrm{B}$, estiveram especialmente relacionados com a reforma da OMS, ainda que o tema de financiamento dos programas também tenha sido objeto em 2013 (quadro 2).

No ano de 2012, quando o CSS se pronunciou como bloco pela primeira vez, em relação à reforma da OMS, o Isags havia realizado uma oficina, três meses antes da
65 a AMS, com o tema Diplomacia da Saúde e Saúde Global. A oficina do Isags reuniu delegados dos Ministérios da Saúde e das Relações Exteriores dos Estados-membros da Unasul, além de especialistas no tema. A reforma da OMS foi objeto de apresentações de especialistas convidados e de debates entre os delegados dos países. A troca de informações e o acúmulo de conhecimento propiciados pela oficina facilitaram $o$ 
processo de posicionamento comum apresentado pelo CSS sobre a Resolução da AMS A65/5 (quadro 2).

A Unasul tem apresentado posicionamentos comuns, tanto no Comitê A como no Comitê B da AMS. Como visto, os temas tratados nesses Comitês se dividem entre assuntos técnicos relacionados à saúde (A) e temas financeiros e administrativos (B) (tabela 1).

Usando como categorias de análise os cinco eixos do Plano Quinquenal, é possível observar que o tema de medicamentos, além de inaugurar os posicionamentos comuns em 2010, se manteve constante em todas as AMS (tabela 1). Dos 25 posicionamentos comuns apresentados pela Unasul entre 2010 e 2014, 8 foram sobre Resoluções que tratavam do tema de medicamentos. Os demais eixos tiveram atuações variadas no decorrer dos anos. Com exceção do eixo de Recursos Humanos, que teve apenas um posicionamento comum no ano de 2014, os demais eixos somaram quatro posicionamentos comuns cada, e os temas financeiros e administrativos do Comitê $\mathrm{B}$ contabilizaram cinco.

Essa concentração dos posicionamentos comuns no tema de medicamentos pode ser explicada por dois fatores: o primeiro é o trabalho contínuo do Grupo Técnico de Acesso Universal de Medicamentos (Gaumu), que, dos cinco GTs do CSS, é o único que, ao longo dos anos, manteve reuniões periódicas e acompanhamento das agendas internacionais. $\mathrm{O}$ outro fator é o desabastecimento de medicamentos, que têm sido uma preocupação global, mas, em especial, dos países em desenvolvimento e não produtores de medicamentos, além da incorporação de tecnologias que vêm gradativamente desfinanciando os sistemas de saúde desses países (GRAY; MANASSE, 2013).

$\mathrm{Na}$ análise dos posicionamentos comuns ao longo dos anos, verifica-se que há continuidade e seguimento dos temas, o que demonstra a atuação da Unasul como ator político no cenário global e a capacidade do bloco de intervir nas agendas, buscando resultados que favoreçam os Estados-membros. Na $63^{\mathrm{a}}$ AMS, por exemplo, a Unasul posicionou-se a favor da criação de um grupo intergovernamental para tratar de mecanismos financeiros inovadores e sustentáveis, a fim de financiar pesquisa e desenvolvimento sobre saúde pública, inovação e propriedade intelectual. Esse Grupo Consultivo de Especialistas para Pesquisa e Desenvolvimento: Financiamento e Coordenação $(C E W G)$ foi criado em 2010 e, nos anos seguintes, a Unasul acompanhou suas atividades. Ainda no eixo de medicamentos, a questão de produtos médicos de baixa qualidade, espúrios, com etiquetas enganosas, falsificados ou de imitação também foi objeto de posicionamento comum da Unasul pela primeira vez em 2010, e foi acompanhado nos dois anos seguintes. O mesmo ocorre com o tema da Deficiência, apresentado em posicionamento comum da Unasul pela primeira vez em 2013, na $66^{\mathrm{a}}$ AMS e consolidado na AMS seguinte, em 2014, com a aprovação do Plano de Ação Mundial da OMS sobre Deficiência 2014-2021. 
Tabela 1. Posicionamentos comuns da Unasul apresentados em relação às resoluções da OMS, segundo o comitê no qual a resolução foi apresentada e temas das resoluções classificados pelos eixos do Plano Quinquenal da Unasul, 2010-2014

\begin{tabular}{|c|c|c|c|c|c|c|c|c|c|}
\hline \multirow[b]{2}{*}{$\begin{array}{c}\text { Ano e No } \\
\text { AMS }\end{array}$} & \multirow{2}{*}{$\begin{array}{c}\text { № de } \\
\text { Resoluções } \\
\text { com posições } \\
\text { comuns da } \\
\text { Unasul }\end{array}$} & \multicolumn{2}{|c|}{ Comitês } & \multicolumn{6}{|c|}{ Temas } \\
\hline & & Comitê A & Comitê B & Medicamentos & $\begin{array}{l}\text { Sistemas } \\
\text { Universais } \\
\text { de Saúde }\end{array}$ & $\begin{array}{l}\text { Recursos } \\
\text { Humanos }\end{array}$ & $\begin{array}{l}\text { Determinação } \\
\text { Social da } \\
\text { Saúde }\end{array}$ & $\begin{array}{l}\text { Vigilância } \\
\text { e Resposta } \\
\text { em Saúde }\end{array}$ & $\begin{array}{l}\text { Financeiros e } \\
\text { Administrativos }\end{array}$ \\
\hline $\begin{array}{l}2010 \\
63 \cong \text { AMS }\end{array}$ & 2 & 2 & - & 2 & - & - & - & - & - \\
\hline $\begin{array}{l}2011 \\
64^{\text {a }} \text { AMS }\end{array}$ & 5 & 4 & 1 & 1 & 2 & - & - & 1 & 1 \\
\hline $\begin{array}{l}2012 \\
65^{a} \text { AMS }\end{array}$ & 2 & 1 & 1 & 1 & - & - & - & - & 1 \\
\hline $\begin{array}{l}2013 \\
66 \text { AMS }\end{array}$ & 6 & 4 & 2 & 2 & 1 & - & 1 & - & 2 \\
\hline $\begin{array}{l}2014 \\
\text { 67a AMS }\end{array}$ & 11 & 10 & - & 2 & 1 & 1 & 3 & 3 & 1 \\
\hline Total & 26 & 21 & 4 & 8 & 4 & 1 & 4 & 4 & 5 \\
\hline
\end{tabular}

Fonte: Elaboração própria.

Nos posicionamentos comuns do CSS, independentemente do eixo temático, são identificadas as defesas de determinadas questões prioritárias para o bloco, que aparecem de forma transversal. Esses eixos transversais demonstram que há, entre os países da Unasul, a despeito das diferenças entre os modelos de saúde adotados por cada país, pontos de aderência que têm tido a capacidade de manter a atuação em bloco da região.

A primeira dessas questões é a necessidade de fortalecimento da liderança da OMS e de seu papel protagônico na definição de políticas de saúde em âmbito global. No final dos anos 1980 e início dos 1990, a United Nations Children's Fund (Unicef), o Banco Mundial, o Programa de Desenvolvimento da ONU, a Fundação Rockefeller e diversos outros atores passaram a ocupar o vácuo criado por uma crescente ineficiência da OMS. No final da década de 1990, a OMS buscava reposicionar-se como um importante ator no cenário global e remodelar-se como uma organização que efetivamente cumprisse a missão para a qual havia sido criada, capaz de monitorar e influenciar outros atores no cenário global (BROWN; CUETO; FEE, 2006).
Quase duas décadas depois, em 2010, a atual Diretora-Geral da OMS, Margaret Chan, retomou os debates sobre a necessidade de reformar a Organização Mundial da Saúde. O tema foi levado à Assembleia Mundial da Saúde um ano depois, durante sua $64^{\text {a }}$ edição, com a decisão consensual dos Estados-membros sobre a necessidade da reforma. A posição do CSS no processo de reforma da OMS tem sido bastante crítica, especialmente sobre: a participação de atores não estatais e a necessidade de que a reforma não se detenha a questões administrativas, mas se aprofunde em temas estruturais, como a governança global em saúde e o debate sobre o financiamento da organização. Contudo, apesar da criticidade, os posicionamentos comuns do bloco enfatizam a importância de fortalecer a liderança da OMS e melhorar seu desempenho como autoridade sanitária global, com maior participação dos Estados-membros.

Outro tema presente em vários dos posicionamentos comuns do CSS é a retomada da prioridade da região das Américas dentro da OMS, a partir da garantia de financiamento suficiente para o desenvolvimento das ações 
da Opas. Em vários biênios foi observada uma redução contínua da transferência de recursos financeiros para a Região das Américas (OPS, 2013). O último orçamento por programas da OMS aprovado, biênio 2014-2015, destinou apenas 4,4\% do orçamento para o Escritório Regional da OMS para as Américas (AMRO). Foi o menor percentual entre as seis regionais, sete vezes menor do que o destinado ao Escritório Regional da África, e quase a metade do destinado ao Oeste Pacífico (GRAY; MANASSE, 2013). O baixo orçamento diminui a capacidade de atuação da Opas, bem como enfraquece as capacidades dos países da região em relação à governança em saúde.

Outra prioridade transversal dos países da América do Sul expressa nos posicionamentos comuns na AMS é a necessidade de aprovação de acordos vinculantes para determinados temas, que são prioritários e necessitam de mais força normativa do que as Resoluções são capazes de propiciar. A ConvençãoQuadro para o Controle do Tabaco (CQCT), que entrou em vigor em fevereiro de 2005, após 40 países a terem ratificado, é o primeiro tratado internacional de saúde pública da história. Diferentemente das Resoluções, que apenas produzem diretrizes em políticas de saúde em nível global, o CQTC, por se tratar de um tratado mundial, é juridicamente vinculante, o que significa que seu cumprimento passa a ser obrigatório a partir de sua entrada em vigor (REYNALES-SHIGEMATSU, 2012).

A defesa da ação intersetorial e de maior articulação entre a OMS e as demais agências das Nações Unidas também aparece como prioridade em diversos posicionamentos comuns do CSS na AMS. Os debates sobre a promoção da saúde, os determinantes sociais e políticos da saúde e a relação entre saúde e desenvolvimento sustentável já concluíram que é impossível combater as inequidades em saúde existentes exclusivamente por meio do setor saúde. É necessário operar através de ações intersetoriais, propiciando ações sinérgicas que impactam a saúde (OTTERSEN ET AL., 2014). Essa prioridade se expressa especialmente nos atuais debates sobre o pós-2015 ou os Objetivos do Desenvolvimento Sustentável (ODS).

Outra questão que aparece transversalmente em diversos posicionamentos comuns é o foco em atender as necessidades dos países em desenvolvimento, ampliando a atuação do CSS para além das fronteiras da América do Sul. Visando fortalecer a cooperação entre países com dificuldades comuns e interesses compartilhados, a cooperação Sul-Sul ocorre pelo intercâmbio de experiências, pela aprendizagem conjunta e pelo compartilhamento de resultados e responsabilidades (SANTANA, 2011).

A ampliação da capacidade da Unasul de traduzir conhecimento e recursos materiais, acumulados regionalmente, em instrumentos de atuação política, depende de sua capacidade de atuar como um agente global, interagindo com outros atores externos à região e estabelecendo bases comuns para a implementação de ideias e consensos na governança da saúde global (RIGGIROZZI, 2012).

\section{Considerações finais}

Kickbush e Buss (2011) destacam que o mundo está passando por uma mudança geopolítica, e os países em desenvolvimento, que antes não tinham como expressar suas necessidades diante dos países desenvolvidos, agora têm uma voz na arena internacional. Com isso, surgiu esta nova compreensão de cooperação Sul-Sul, com ênfase na importância da assistência mútua. A Unasul compreendeu que agregar os países do 'sul global' em torno de interesses comuns pode fortalecer as posições da região não somente na AMS, como também em outros foros internacionais multilaterais.

Em uma época na qual as questões de saúde transcendem fronteiras, foi necessário desenvolver uma nova abordagem à diplomacia para que esses desafios transnacionais de saúde pudessem ser resolvidos de forma 
conjunta pelos países (KICKBUSH; BERGER, 2010). A diplomacia da saúde global busca captar tanto o sistema quanto o método dos processos de negociações em relação aos diversos níveis e atores que modelam e gerem o ambiente político global no âmbito da saúde. Nesse contexto de mudança geopolítica, os países perceberam, cada vez mais, que a diplomacia da saúde global oferece grande potencial para lidar com esta rápida transformação (KICKBUSH; BUSS, 2011). Na América do Sul, o Conselho de Saúde Sul-Americano inaugurou o exercício dessa diplomacia diferenciada com foco na saúde como impulsor para o desenvolvimento regional, a partir da formação de consenso entre seus Estadosmembros e da definição de posicionamentos comuns nos foros internacionais.

A atuação da Unasul, por meio de posicionamentos comuns na Assembleia Mundial da Saúde, ao longo dos últimos cinco anos, claramente traz visibilidade ao processo de integração regional na América do Sul e fortalece a própria Unasul como um player global na agenda mundial da saúde, através do exercício da diplomacia da saúde. O acompanhamento dos temas ao longo dos anos indica maturidade do bloco na definição das prioridades e das posições políticas defendidas, visando alcançar objetivos de interesses comuns.

Contudo, há questões nas quais a Unasul e o CSS podem avançar, com o objetivo de ampliar e qualificar sua atuação na arena global. Buscando colaborar com os próximos passos deste processo, apontamos alguns dos possíveis caminhos.

A primeira questão é a informalidade da representação da Unasul na AMS, o que ainda limita sua atuação. $\mathrm{O}$ reconhecimento do bloco como um observador, com assento garantido na AMS, poderá ser o próximo passo na consolidação da Unasul como um player na arena da saúde.

Além da formalização de sua participação, consideramos que o CSS pode potencializar sua ação como player global organizando-se por meio de reuniões virtuais e presenciais, realizando o acompanhamento das agendas do Conselho Executivo da OMS e da AMS, e participando de outros eventos globais temáticos, promovidos ou não pela OMS. Nessas arenas, a Unasul pode construir alianças com outras regiões e países que possam fortalecer as posições e valores defendidos pelo bloco, e somar votos, pois a Unasul representa apenas 12 votos em um universo total de 194. O sul global deve ser o parceiro principal buscado pela Unasul, especialmente outros blocos de países do sul, como a União Africana; o grupo formado por Brasil, Rússia, Índia, China e África do Sul (Brics); a Caricom; o Consejo de Ministros de Salud de Centroamérica y República Dominicana (Comisca); a Comunidade dos Países de Língua Portuguesa (CPLP) e a Southern Africa Development Community (SADC). Porém, a diplomacia sanitária exercida pela Unasul poderá agregar também países da Europa e o Canadá, por exemplo, visto os valores e princípios que aparecem transversalmente em seus posicionamentos comuns, em questões de saúde global.

Outro ponto fundamental é gerar dados e evidências sobre as prioridades regionais, que virão a se tornar posições comuns da Unasul. É necessário aprender com os grandes players globais, como os países do norte e instituições como o Banco Mundial, que convencem com seus números e apresentam informações consistentes neles baseadas, desenvolvendo capacidade técnica e fortalecendo sua capacidade de negociação. Oficinas, seminários e reuniões que permitem aos países da Unasul compartilhar informações, conhecimentos, desafios e boas práticas sobre os problemas de saúde devem ser estimulados, visto que são ferramentas fundamentais para a construção de políticas regionais, bem como para a efetivação de acordos bilaterais e a transferência de conhecimento entre seus Estados-membros.

Fortalecer a região por meio de políticas e ações intersetoriais é importante 
para ampliar a atuação da Unasul na arena global, para além da saúde. A Unasul conta com outros 11 Conselhos Ministeriais e um Conselho de Ministros de Relações Exteriores. Quando essa estrutura começar a coordenar suas ações e atuar em conjunto, em diferentes arenas globais, o bloco poderá melhorar muito sua posição de player global.

Finalmente, o CSS e a Unasul precisam se aproximar da sociedade civil e da academia sul-americana. A construção de laços com os movimentos sociais e a academia, na América do Sul, são importantes passos para construir uma nova governança democrática em saúde na região. Esses atores regionais têm lutado pela saúde e pela democracia por muitas décadas, e devem ser aliados da Unasul. É necessário fomentar a participação cidadã, a partir de mecanismos como conselhos e consultas públicas.

\section{Referências}

BROWN, T. M.; CUETO, M.; FEE, E. A transição de saúde pública 'internacional' para 'global' e a Organização Mundial da Saúde. História, Ciências, Saúde Manguinhos, Rio de Janeiro, v. 13, n. 3, p. 623-647, 2006.

BUSS, P. M.; FERREIRA, J. R. Cooperação e integração regional em saúde na América do Sul: a contribuição da UNASUL Saúde. Ciência \&t Saúde Coletiva, Rio de Janeiro, v. 16, n. 6, p. 2699-2711, 2011.

GRAY, A.; MANASSE, H. R. Shortages of medicines: a complex global challenge. 2013. Disponível em: $<$ http:// www.who.int/bulletin/volumes/90/3/11-101303/en/\#. U0woc7GDYeQ.mendeley>. Acesso em: $26 \mathrm{dez} .2014$.

KICKBUSH, I.; BERGER, C. Diplomacia de saúde global. Revista Eletrônica de Comunicação, Informação e Inovação em Saúde, Rio de Janeiro, v. 4, n. 1, p. 19-24, 2010.

KICKBUSH, I.; BUSS, P. Global Health Diplomacy and Peace. Infectious Disease Clinics of North America, New York, v. 25, n. 3, p. 601-10, 2011.

MINELLI, E. World Health Organization: the mandate of a specialized agency of the United Nations. 2006. 196 f. Monografia (Graduação em Political Science, especializando em International Relations) - Catholic University of Milan, Milão, 2006. Disponível em: <http://www.gfmer.ch/TMCAM/WHO_Minelli/P1-4. htm>. Acesso em: 4 out. 2014.

ORGANIZACIÓN MUNDIAL DE LA SALUD (OMS). Reglamento Interno del Consejo Ejecutivo de la Organización Mundial de la Salud. Decisión EB134(3). 2014a. Disponível em: <http://apps.who.int/gb/ebwha/ pdf_files/EB134/B134_3-en.pdf>. Acesso em: 12 nov. 2015.

Reglamento Interno de la Asamblea Mundial de la Salud. Resolución WHA66.18. 2014b. Disponível em: <http://apps.who.int/gb/ebwha/pdf_files/WHA66/ A66_R18-sp.pdf>. Acesso em: 12 nov. 2015.

ORGANIZACIÓN PANAMERICANA DE LA SALUD (OPS). Resolución CE152.SS.R1. Asignación de Fondos de la OMS a la Región de las Américas. 152a Sesión del Comité Ejecutivo, 29 de abril del 2013. Disponível em: $<$ http://www.paho.org/hq/index.php?option=com docman\&task=doc_download\&gid=21330\&Itemid=721 \&lang=en>. Acesso em: 12 nov. 2015.

OTTERSEN, O. P. et al. As origens politicas das inequidades em saúde: perspectivas de mudança. The Lancet - Comissão da Universidade de Oslo sobre Governança Global em Saúde. 2014. Disponível em: <http://www.abrasco.org.br/UserFiles/Image/ Lancet\%20Oslo\%20Sumario\%20Executivo\%20portugues.pdf>. Acesso em: 12 nov. 2015.

\section{PERMANENT MISSION OF SWITZERLAND TO} THE UNITED NATIONS. The PGA Handbook: a practical guide to the United Nations General Assembly. New York, 2011. Disponível em: <https:// www.eda.admin.ch/content/dam/eda/en/documents/ publications/InternationaleOrganisationen/Uno/UNpga-handbook_en.pdf>. Acesso em: 5 fev. 2015.

QUEIROZ, L. G.; GIOVANELLA, L. Agenda regional da saúde no Mercosul: arquitetura e temas. Rev. Panam. Salud Pública, Washington, DC, v. 30, n. 2, p. 182-188, 2011. 
REYNALES-SHIGEMATSU, L. M. El control del tabaco, estrategia esencial para reducir las enfermedades crónicas no transmisibles. Salud Pública Méx., Cuernavaca, v. 54, n. 3, jun. 2012. Disponível em: <http://www.scielo.org.mx/scielo.php?script=sci arttext\&pid=S0036-36342012000300015\&lng=es\&nrm =iso>. Acesso em: 27 dez. 2014.

RIGGIROZZI, P. Acción colectiva y diplomacia de UNASUR Salud: la construcción regional a través de políticas sociales. Buenos Aires: FLACSO, 2012. (Documento de trabajo, 63).

SANTANA, J. P. Um olhar sobre a cooperação sul-sul em saúde. Ciênc. Saúde Coletiva, Rio de Janeiro, v. 16, n. 6, p. 2415-2424, 2011.

\section{UNIÓN DE NACIONES SURAMERICANAS}

(UNASUR). Decisión para el Establecimiento del Consejo de Salud Suramericano de la Unasur. 17 de dezembro de 2008a. Disponível em: <http://www.unasursg.org/ images/descargas/ESTATUTOS\%20CONSEJOS\%20 MINISTERIALES\%20SECTORIALES/ ESTATUTO\%20CONSEJO\%20DE\%20SALUD.pdf>. Acesso em: 3 out. 2014.
Plan Quinquenal 2010-2015 Consejo de Salud Suramericano. 28 de abril de 2010. Disponível em: <http://www.isags-unasur.org/it_biblioteca. php?lg=2\&cat $=1 \& b b=67>$. Acesso em: 3 out. 2014.

Tratado Constitutivo de la Unión de Naciones Suramericanas. 23 de maio de 2008a. Disponível em: $<$ http://www.isags-unasur.org/documentos_interna.asp? lang=3\&idArea $=26 \&$ idPai $=2421>$. Acesso em: 3 out. 2014.

VAN DE PAS, R.; VAN SCHAIK, L. Democratizing the World Health Organization. Public Health, New York, v. 128, n. 2, p. 195-201, 2014. Disponível em: <http://dx.doi. org/10.1016/j.puhe.2013.08.023>. Acesso em: 12 nov. 2015.

VENTURA, D. Saúde pública e política externa brasileira. Conecta Direitos Humanos, São Paulo, v. 10, n. 19, 2013. Disponível em: <http://www.conectas.org/pt/ acoes/sur/edicao/19/1000466-saude-publica-e-politica-externa-brasileira>. Acesso em: 12 nov. 2015.

Recebido para publicação em abril de 2015

Versão final em setembro de 2015

Conflito de interesses: inexistente

Suporte financeiro: não houve 